\title{
Synthesis and properties of MoAlB composites reinforced with $\mathrm{SiC}$ particles
}

\author{
Weiwei ZHANG ${ }^{a}$, Shibo $\mathrm{LI}^{a, b, *}$, Shuang $\mathrm{WU}^{a}$, Boxiang YAO ${ }^{a}$, Shukai FAN ${ }^{c}$, \\ Guoping $\mathrm{BEI}^{c}$, Wenbo $\mathrm{YU}^{a, b}$, Yang ZHOU ${ }^{a, b}$, Ying $\mathrm{WU}^{d}$, Sun-An $\mathrm{DING}^{d}$ \\ ${ }^{a}$ Center of Materials Science and Engineering, School of Mechanical and Electronic Control Engineering, \\ Beijing Jiaotong University, Beijing 100044, China \\ ${ }^{b}$ Research Center of Rail Vehicles Safety Monitoring and Health Management, \\ Beijing Jiaotong University, Beijing 100044, China \\ ${ }^{c}$ China Porcelain Fuchi (Suzhou) High Tech Nano Materials Co., Ltd., Suzhou 215100, China \\ ${ }^{d}$ School of Microelectronics, Southern University of Science and Technology, Shenzhen 518055, China
}

Received: September 8, 2021; Revised: September 19, 2021; Accepted: October 1, 2021

(C) The Author(s) 2021.

\begin{abstract}
Novel MoAlB composites reinforced with 5-15 vol\% SiC have been firstly prepared and characterized in the present study. The $\mathrm{SiC}$ reinforcement is stable with MoAlB at a sintering temperature of $1200{ }^{\circ} \mathrm{C}$ in Ar. The $5 \mathrm{vol} \% \mathrm{SiC} / \mathrm{MoAlB}$ composite exhibited improved mechanical properties and enhanced oxidation resistance. A flexural strength of $380 \mathrm{MPa}$ and a Vickers hardness of $12.7 \mathrm{GPa}$ were achieved and increased by $24 \%$ and $51 \%$, respectively, as compared with those for MoAlB, indicating the enhanced strengthening effect of SiC. Cyclic oxidation tests at 1200 and $1300{ }^{\circ} \mathrm{C}$ for $10 \mathrm{~h}$ in air showed that the $5 \mathrm{vol} \% \mathrm{SiC} / \mathrm{MoAlB}$ composite has better oxidation resistance than MoAlB due to the formation of a dense and continuous scale composed of $\mathrm{Al}_{2} \mathrm{O}_{3}$ and $\mathrm{SiO}_{2}$, which prevents the oxygen inward diffusion and the evaporation of oxides. We expect that the general strategy of second phase reinforcing for materials will help to widen the applications of MoAlB composites.
\end{abstract}

Keywords: SiC/MoAlB composite; mechanical properties; oxidation; microstructure

\section{Introduction}

MoAlB is an attractive ternary boride in MAB phase family (where $\mathrm{M}$ is a transition metal, $\mathrm{A}$ is aluminium or zinc, and B is boron [1]) not only due to its ease of fabrication and densification at relatively lower temperatures $\left(1050-1200{ }^{\circ} \mathrm{C}\right)$ but also to its excellent high temperature oxidation resistance as compared with the vast majority of binary transition metal

\footnotetext{
* Corresponding author.

E-mail: shbli1@bjtu.edu.cn
}

borides. The binary transition metal borides generally require high temperatures above $1700{ }^{\circ} \mathrm{C}$ to achieve full density, but have poor oxidation resistance at temperatures above $1000{ }^{\circ} \mathrm{C}$ [2].

MoAlB, as the most studied MAB phase, has been widely investigated from theoretical simulations [3-5] to experimental studies, and exhibits attractive mechanical properties, high temperature properties, radiation tolerance, and ablation resistance [6-12]. So far, MoAlB as the only one in the MAB phase family has been demonstrated with better oxidation resistance than other $\mathrm{Al}$-containing $\mathrm{MAB}$ phases (such as $\mathrm{Fe}_{2} \mathrm{AlB}_{2}$ and $\mathrm{Cr}_{2} \mathrm{AlB}_{2}$ ) at temperatures below $1300{ }^{\circ} \mathrm{C}$ due to 
the formation of a dense and continuous $\alpha-\mathrm{Al}_{2} \mathrm{O}_{3}$ layer [13-16]. The oxidation resistance of MoAlB is even better than that of $\mathrm{Ti}_{2} \mathrm{AlC}$ and $\mathrm{Cr}_{2} \mathrm{AlC}$ MAX phases at $1100{ }^{\circ} \mathrm{C}$ [17-19]. For example, the oxidation rate constant $K_{\mathrm{c}}$ of MoAlB is about $7.1 \times 10^{-23} \mathrm{~m}^{3} / \mathrm{s}$ at $1100{ }^{\circ} \mathrm{C}$ [8], lower than $1.0 \times 10^{-21}-1.8 \times 10^{-21} \mathrm{~m}^{3} / \mathrm{s}$ for $\mathrm{Ti}_{2} \mathrm{AlC}$ [17]. However, increasing oxidation temperature leads to the rapid mass gains of MoAlB. To further improve its oxidation resistance, the replacement of some $\mathrm{Al}$ by $\mathrm{Si}$ in MoAlB to form a Mo(Al,Si)B solid solution has been designed because the dissolved $\mathrm{Si}$ can be oxidized to $\mathrm{SiO}_{2}$ which retards the inner diffusion of $\mathrm{O}$ upon oxidation. The $\mathrm{Mo}(\mathrm{Al}, \mathrm{Si}) \mathrm{B}$ solid solution exhibited better oxidation resistance than its natural counterpart [19]. In the temperature range of $1200-1400{ }^{\circ} \mathrm{C}$, the mass gain and the scale thickness of Mo(Al,Si)B are lower than those of MoAlB [19]. The above results confirm that $\mathrm{Si}$ can effectively improve the oxidation resistance of MoAlB. However, the solubility of $\mathrm{Si}$ in MoAlB is limited, with the maximum solubility of $\sim 0.91$ at $\% \mathrm{Si}$ [20], causing the difficult study of the influence of Si content on the oxidation behavior of MoAlB.

Another facile route to enhance the oxidation resistance of MoAlB is the incorporation of ceramic particles. Among ceramic particles, $\mathrm{SiC}$ is preferred to reinforce MoAlB due to the following two reasons. First, $\mathrm{SiC}$ has high hardness and excellent oxidation resistance. Second, $\mathrm{SiC}$ has been proved to be a good reinforcement in MAX composites. The incorporation of $\mathrm{SiC}$ in $\mathrm{Ti}_{3} \mathrm{SiC}_{2}$ matrix is one of the simplest yet effective approaches to prepare composites with greatly improved mechanical properties and high temperature oxidation resistance [21-26]. Up to now, to the best of our knowledge, there are no reports on the synthesis and characterization of SiC/MoAlB composites.

In the present study, the main purpose is to prepare $\mathrm{SiC} / \mathrm{MoAlB}$ composites for the first time. The mechanical properties and oxidation resistance of composites were investigated. The phase composition and microstructure of the prepared composites were characterized.

\section{Experimental}

\section{1 Material preparation}

To prepare MoAlB samples, Mo (-300 mesh, 99.5\% purity, General Research Institute for Nonferrous Metals GRINM, China), Al (-300 mesh, 99.5\% purity,
Beijing Reagent Company, China), and B (-300 mesh, 99\% purity, GRINM, China) powders with a molar ratio of Mo:Al:B = 1:1.3:1 were mixed for $10 \mathrm{~h}$, and then pressureless-sintered at $1200{ }^{\circ} \mathrm{C}$ for $1 \mathrm{~h}$ in $\mathrm{Ar}$ atmosphere. The sintered samples were pulverized, and then sieved with a 200 meshed sieve to obtain MoAlB powders.

To prepare SiC/MoAlB composites, powders of SiC (an average size of $\sim 28 \mu \mathrm{m},>99 \%$ purity, GRINM, China) and MoAlB were mixed for $10 \mathrm{~h}$, and then hot pressed at $1200{ }^{\circ} \mathrm{C}$ under $25 \mathrm{MPa}$ for $1 \mathrm{~h}$ in $\mathrm{Ar}$ atmosphere. The volume contents of $\mathrm{SiC}$ are 5, 10, and $15 \mathrm{vol} \%$.

\section{2 Mechanical property measurement}

The prepared $\mathrm{SiC} / \mathrm{MoAlB}$ samples were cut into bars with different sizes by a wire electrical discharge machine. The bars were polished to $1 \mu \mathrm{m}$ by diamond paste, cleaned with ethanol, and then dried in an oven at $50{ }^{\circ} \mathrm{C}$ for $4 \mathrm{~h}$. The different-sized bars were used for mechanical properties and oxidation tests.

$3 \mathrm{~mm} \times 4 \mathrm{~mm} \times 36 \mathrm{~mm}$ bars were used to measure the flexural strength by the three-point bending test in a WDW-100E compression machine (China). The span size and crosshead speed were $30 \mathrm{~mm}$ and $0.5 \mathrm{~mm} / \mathrm{min}$, respectively.

The Vickers hardness test was performed in a TH700 hardness tester under loads of $1-20 \mathrm{~kg}$ with a dwelling time of $15 \mathrm{~s}$. Six measurements in different areas were performed for each sample to obtain an average value.

\section{3 Oxidation test}

$3 \mathrm{~mm} \times 4 \mathrm{~mm} \times 10 \mathrm{~mm}$ bars were used to investigate the cyclic oxidation behavior in a TSK-5-14 high temperature tube furnace at 1200 and $1300{ }^{\circ} \mathrm{C}$ for $10 \mathrm{~h}$ in air. The weight gain was measured at the interval of $2 \mathrm{~h}$. The weight change of the samples was measured using an analytical balance with an accuracy of $0.0001 \mathrm{~g}$, and converted into a specific weight change per surface area. The oxidized samples were used to the following microstructure and phase characterization.

\section{4 Characterization}

The phase compositions of mixtures, hot-pressed samples before and after oxidation were analyzed by $\mathrm{X}$-ray diffraction (XRD) analysis using an Ultima IV 
diffractometer (Rigaku, Japan) with $\mathrm{Cu} \mathrm{K} \alpha$ radiation $(\lambda=0.154 \mathrm{~nm})$ operated at $40 \mathrm{kV}$ and $40 \mathrm{~mA}$. The morphologies of mixture powders, polished and fractured surfaces of hot-pressed samples, and oxide scale were characterized with a ZEISS EVO 18 scanning electron microscope (SEM; Carl Zeiss SMT, Germany) equipped with an energy dispersive spectrometer (EDS) system.

For transmission electron microscopy (TEM) examination, focused ion beam (FIB) cross-section was prepared with a dual-beam FIB/SEM (FEI Scios, USA) by using a $\mathrm{Ga}^{+}$ion source operating at $30 \mathrm{kV}$. A thin slice representing a cross-sectional cut perpendicular to the SiC/MoAlB boundary was analyzed by an FEI Talos F200X (FEI, USA) TEM with an operating voltage of $200 \mathrm{kV}$.

\section{Results}

\section{1 Preparation and characterization of SiC/MoAlB composites}

MoAlB composites reinforced with 5, 10, and 15 vol\% $\mathrm{SiC}$ were prepared by hot pressing at $1200{ }^{\circ} \mathrm{C}$ under $25 \mathrm{MPa}$ for $1 \mathrm{~h}$ in Ar atmosphere. Figure 1 presents the $\mathrm{XRD}$ results for the prepared composites. The composites are primarily composed of MoAlB and $\mathrm{SiC}$, with a small amount of $\mathrm{Al}_{3} \mathrm{Mo}$. No new phases were found in the XRD patterns, which probably indicated that no reaction happened between $\mathrm{SiC}$ and $\mathrm{MoAlB}$ at the sintering temperature of $1200{ }^{\circ} \mathrm{C}$. The back-scattered SEM micrograph (Fig. 2(a)) depicts the distribution of $\mathrm{SiC}$ particles (black color) with irregular shapes in the 10 vol\% SiC/MoAlB composite. SiC particles with an average size of $\sim 28 \mu \mathrm{m}$ were homogeneously distributed in MoAlB matrix (with sizes of less than $40 \mu \mathrm{m}$ ). $\mathrm{Al}_{3} \mathrm{Mo}$ (light grey color in Fig. 2(a)) and $\mathrm{Al}_{2} \mathrm{O}_{3}$ (small black particles in Fig. 2(b)) as impurity phases appeared, which should be from the initial MoAlB powders. No $\mathrm{Al}_{2} \mathrm{O}_{3}$ peaks were detected in the XRD patterns (Fig. 1), possibly due to their amount below the detection limit of XRD. An enlarged SEM image, taken from the dashed rectangle area in Fig. 2(a), clearly shows the boundary areas between $\mathrm{SiC}$ and MoAlB particles (Fig. 2(b)). Neither new formed phases nor reaction layers could be detected in the boundary areas, confirming the thermal stability of SiC with MoAlB at $1200{ }^{\circ} \mathrm{C}$.

TEM analysis was performed to further examine the microstructure of the $5 \mathrm{vol} \% \mathrm{SiC} / \mathrm{MoAlB}$ composite. Figure 3(a) shows the TEM analysis of a representative $\mathrm{SiC} / \mathrm{MoAlB}$ phase boundary. No reaction zones are observed in the phase boundary. A high resolution TEM (HRTEM) image presents the lattice fringes of $\mathrm{SiC}$ and MoAlB (Fig. 3(b)). The measured interplanar

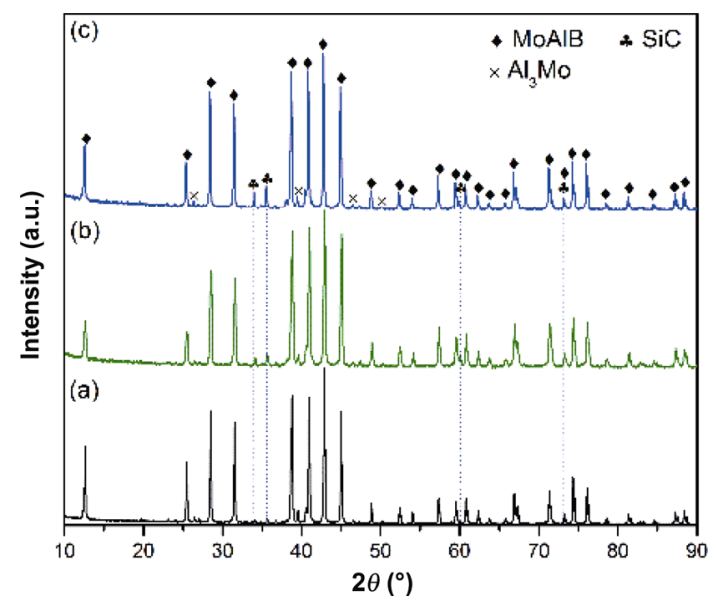

Fig. 1 XRD patterns of (a) 5 vol\%, (b) 10 vol $\%$, and (c) $15 \mathrm{vol} \% \mathrm{SiC} / \mathrm{MoAlB}$ composites.
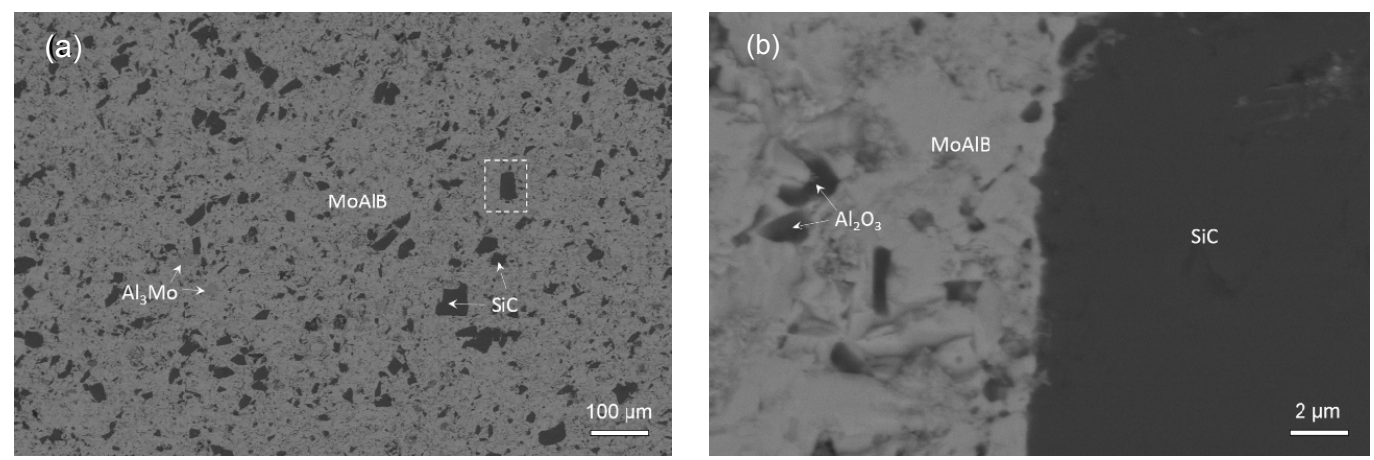

Fig. 2 Back-scattered SEM micrographs of the polished surface of 10 vol\% SiC/MoAlB: (a) a low magnification image and (b) a high magnification image taken from (a). 

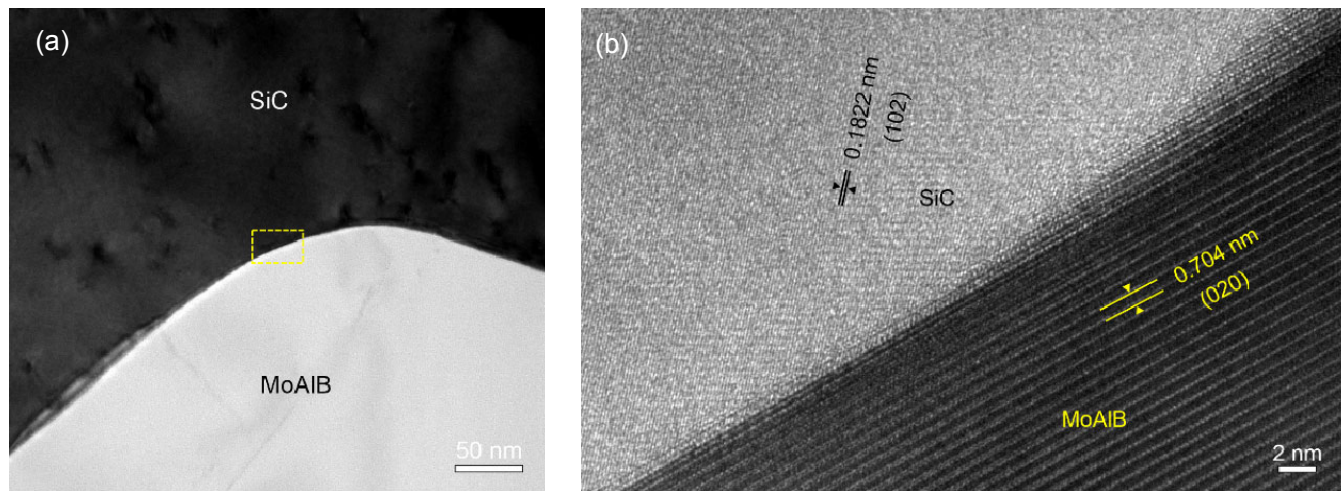

Fig. 3 (a) TEM image of SiC/MoAlB and (b) HRTEM image of the zone marked with a dashed rectangle in (a).

spacing is $\sim 0.1822 \mathrm{~nm}$ corresponding to the (102) plane of $\mathrm{SiC}$ and $0.704 \mathrm{~nm}$ corresponding to the (020) plane of MoAlB. The HRTEM image reveals that the interface is clean and continuous, without new phases or amorphous phases at the interface, further confirming the stability of $\mathrm{SiC}$ with MoAlB at the sintering temperature.

\section{2 Mechanical properties}

The measured mechanical properties as a function of reinforcing phase content are presented in Fig. 4. A flexural strength of $380 \mathrm{MPa}$ and a Vickers hardness of 12.7 $\mathrm{GPa}$ have been successfully achieved in the 5 vol\% $\mathrm{SiC} / \mathrm{MoAlB}$ composite and increased by $24 \%$ and $51 \%$, respectively, as compared with $306 \mathrm{MPa}$ and 8.4 GPa for MoAlB. However, both the strength and the hardness decrease with the increase of $\mathrm{SiC}$ content (Figs. 4(a) and 4(b), respectively). The deterioration of the mechanical properties should be caused by the decreased relative density. Under the hot pressing conditions of $1200{ }^{\circ} \mathrm{C}$ with $25 \mathrm{MPa}$, the $5 \mathrm{vol} \%$ $\mathrm{SiC} / \mathrm{MoAlB}$ composite has a relative density of $\sim 92.6 \%$,
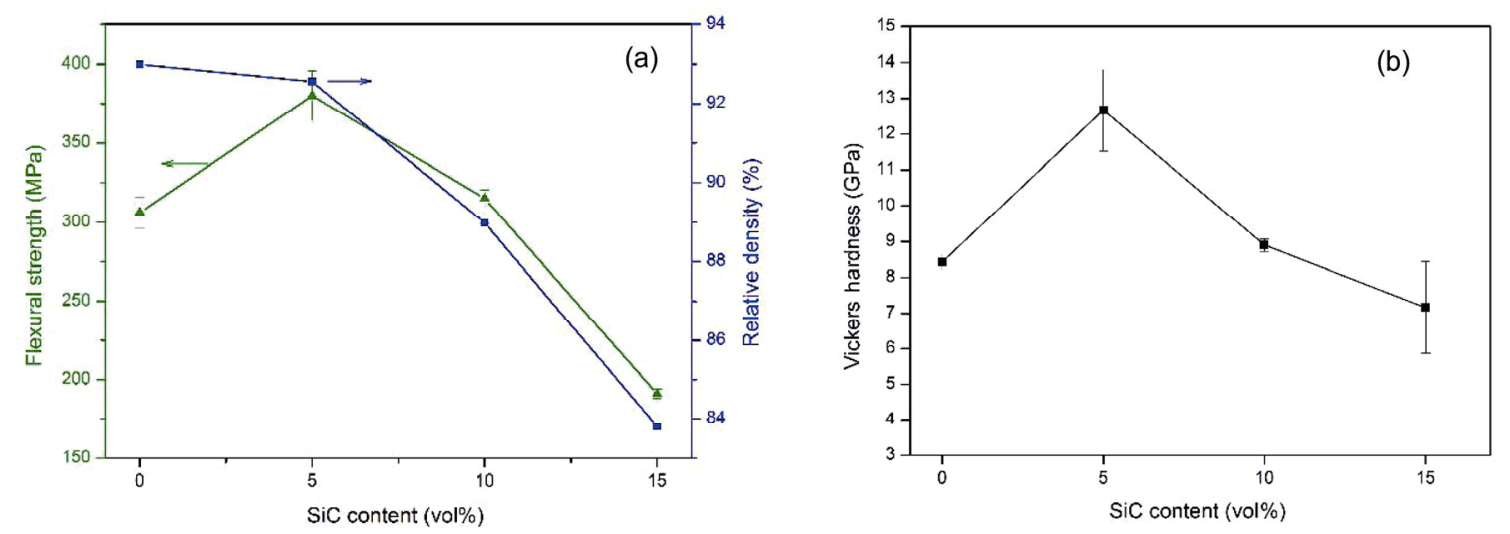

Fig. 4 (a) Flexural strength and (b) Vickers hardness of SiC/MoAlB composites, together with those of MoAlB for comparison. 

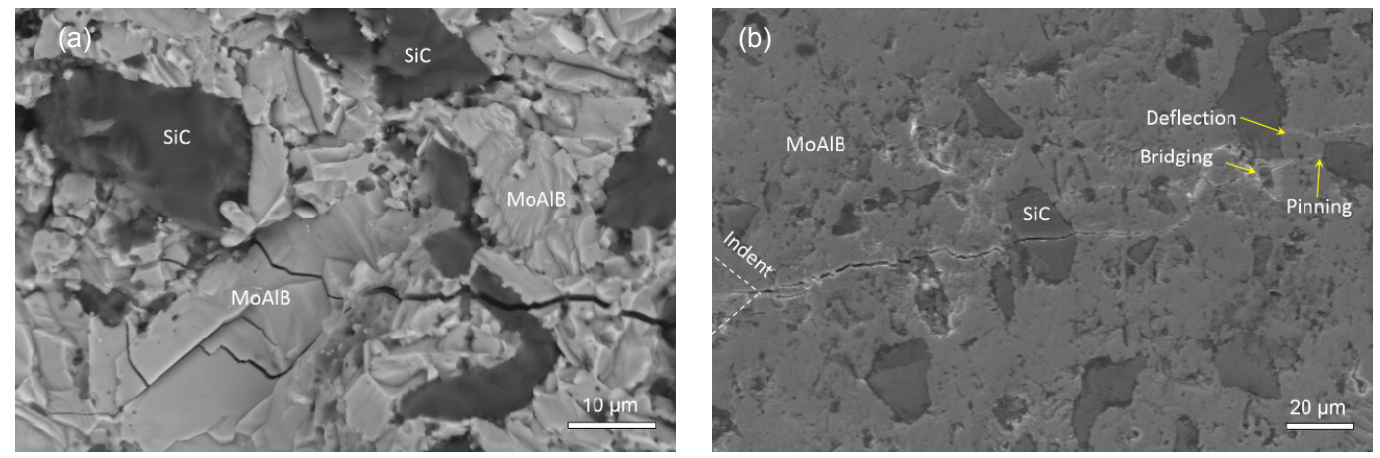

Fig. 5 SEM micrographs of crack propagation paths in the 5 vol\% SiC/MoAlB composite: (a) a back-scattered electron image of the fractured surface and (b) a second electron image of a crack emanating from the indentation corner.

\section{3 Oxidation behavior}

Figure 6(a) depicts the oxide scale thickness as a function of time after cyclic oxidation at 1200 and $1300{ }^{\circ} \mathrm{C}$ for $10 \mathrm{~h}$ in air. The scale thicknesses of $\mathrm{SiC} / \mathrm{MoAlB}$ are lower than those of MoAlB, i.e., $2.0 \mathrm{vs.}$ $2.7 \mu \mathrm{m}$ after oxidation at $1200{ }^{\circ} \mathrm{C}$, and 3.9 vs. $5 \mu \mathrm{m}$ after oxidation at $1300{ }^{\circ} \mathrm{C}$. This result indicates that the scale growth rate on the $\mathrm{SiC} / \mathrm{MoAlB}$ samples is slower than that on the MoAlB samples. The crosssectional back-scattered SEM micrographs present the continuous oxide scales after oxidation at $1200{ }^{\circ} \mathrm{C}$ (Fig. 6(b)) and $1300{ }^{\circ} \mathrm{C}$ (Fig. 6(c)). The formed scales are thin and dense, and mainly composed of $\mathrm{Al}_{2} \mathrm{O}_{3}$.

The XRD result demonstrates that $\mathrm{Al}_{2} \mathrm{O}_{3}$ is the main oxide phase after cyclic oxidation at $1200{ }^{\circ} \mathrm{C}$ (Fig. 7(a)). Diffraction peaks with strong intensities belonging to MoAlB are detected, further confirming the thinner scale. No SiC peaks are detected, possibly due to that some $\mathrm{SiC}$ are oxidized and the residual $\mathrm{SiC}$ with content exceeds the detection limit of XRD. A broaden peak with low intensity locating at the diffraction angle of $\sim 20^{\circ}$ may be contributed by the amorphous
$\mathrm{SiO}_{2}$ (Fig. 7(a)). The morphologies of oxides on the composite are illustrated in Figs. 7(b)-7(d). On the oxidized surface, $\mathrm{SiO}_{2}$ particles are larger, while $\mathrm{Al}_{2} \mathrm{O}_{3}$ particles are smaller and irregular (Figs. 7(b) and 7(c)). The compositions of the two phases are identified by EDS (Fig. 7(d)). The surfaces of $\mathrm{SiO}_{2}$ particles are smooth, suggesting the viscous phase formed at above $1200{ }^{\circ} \mathrm{C}$. Small pores formed in the $\mathrm{Al}_{2} \mathrm{O}_{3}$ scale are irregular, whereas these formed in the $\mathrm{SiO}_{2}$ particles are round. The appearance of round pores confirms the evaporation of gas phases from the viscous $\mathrm{SiO}_{2}$ particles upon oxidation at high temperatures. It should be noted that the pores became much round in the $\mathrm{SiO}_{2}$ particles after oxidation at $1300{ }^{\circ} \mathrm{C}$ (Fig. 7(c)). This feature suggests that the higher the temperature, the lower the viscosity of the formed $\mathrm{SiO}_{2}$ glass phase. The formation of the viscous $\mathrm{SiO}_{2}$ glass phase at high temperatures is beneficial to sealing the channels for the inward diffusion of $\mathrm{O}$ and the outward diffusion of elements from the matrix, contributing to the improvement of oxidation resistance especially at the early stage of oxidation.
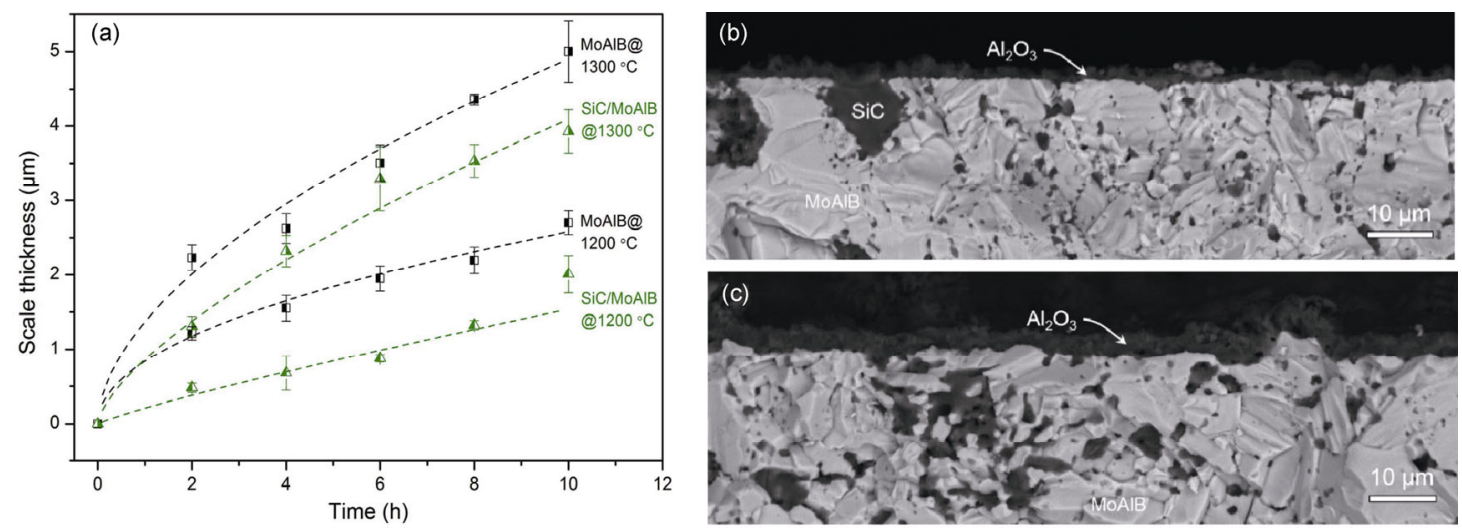

Fig. 6 (a) Scale thickness as a function of oxidation time for 5 vol\% SiC/MoAlB composite. Cross-sectional back-scattered SEM micrographs of the composite after oxidation at (b) $1200{ }^{\circ} \mathrm{C}$ and (c) $1300{ }^{\circ} \mathrm{C}$ for $10 \mathrm{~h}$ in air. 

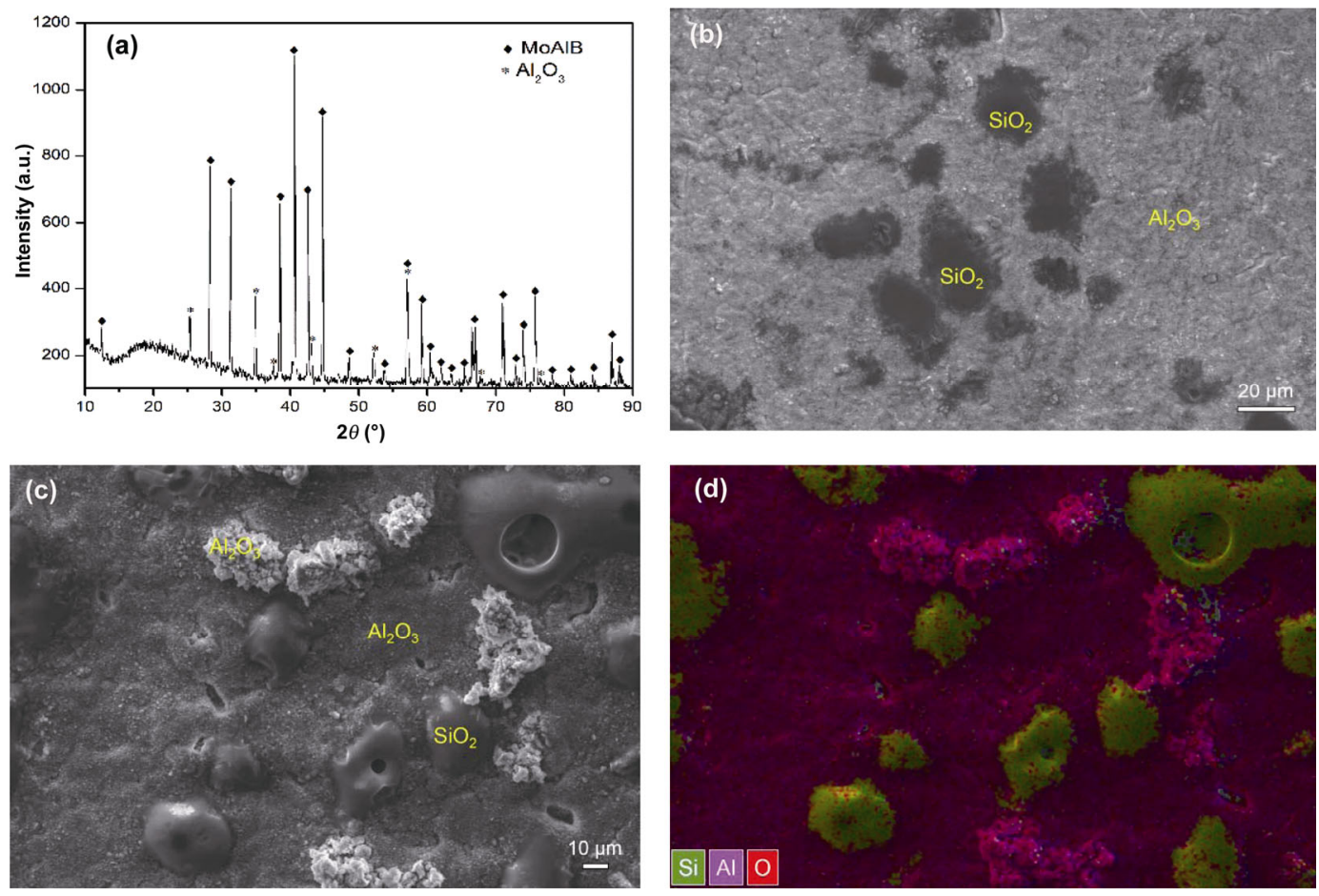

Fig. 7 (a) XRD pattern of $5 \mathrm{vol} \% \mathrm{SiC} / \mathrm{MoAlB}$ composite after oxidation at $1200{ }^{\circ} \mathrm{C}$ for $10 \mathrm{~h}$. SEM micrographs of oxides on the composite after oxidation at (b) $1200{ }^{\circ} \mathrm{C}$ and (c) $1300{ }^{\circ} \mathrm{C}$ for $10 \mathrm{~h}$ in air. (d) EDS mapping for (c).

\section{Discussion}

Fully dense MoAlB bulk samples are not easy to obtain under hot pressing conditions, possibly due to the existence of small pores caused by the evaporation of $\mathrm{MoO}_{3}$ or $\mathrm{B}_{2} \mathrm{O}_{3}$ formed with the absorbed $\mathrm{O}$ at sintering temperatures. For example, a relative density of $94 \%$ is achieved for the MoAlB samples by hot pressing of $\mathrm{MoB}$ and $\mathrm{Al}$ powders at $1200{ }^{\circ} \mathrm{C}$ with $39 \mathrm{MPa}$ for $5.8 \mathrm{~h}$ in vacuum [16]. In the present study, a relative density of about $93 \%$ for MoAlB was prepared by hot pressing of a mixture of $\mathrm{Mo}, \mathrm{Al}$, and $\mathrm{B}$ at $1200{ }^{\circ} \mathrm{C}$ with $25 \mathrm{MPa}$ for $1 \mathrm{~h}$ in Ar. No full density obtained in the SiC/MoAlB composites should not only be ascribed to the above reason, but also to the absence of sintering reactions between $\mathrm{SiC}$ and MoAlB phases. This has been confirmed by the SEM and TEM examinations (Figs. 2 and 3, respectively). The densification of composites without sintering reactions has always been a major challenge. For example, relative densities of $94.4 \%$ and $95 \%$ are obtained, respectively, in monolithic $\mathrm{CrB}_{2}$ and $5 \mathrm{wt} \% \mathrm{MoSi}_{2} / \mathrm{CrB}_{2}$ composite after hot pressing at $1400{ }^{\circ} \mathrm{C}$ under $35 \mathrm{MPa}$ for $2 \mathrm{~h}$ [28]. To further increase the density of $\mathrm{SiC} / \mathrm{MoAlB}$ composites, hot isostatic pressing or spark plasma sintering can be considered. It is reasonable to believe if the density of $\mathrm{SiC} / \mathrm{MoAlB}$ composites was improved, the properties would be further enhanced.

Upon high temperature oxidation, the following oxidation reactions occur:

$$
\begin{gathered}
2 \mathrm{MoAlB}(\mathrm{s})+6 \mathrm{O}_{2}(\mathrm{~g})=\mathrm{Al}_{2} \mathrm{O}_{3}(\mathrm{~s})+\mathrm{B}_{2} \mathrm{O}_{3}(\mathrm{~g})+2 \mathrm{MoO}_{3}(\mathrm{~g})(\mathrm{s}) \\
\mathrm{SiC}(\mathrm{s})+2 \mathrm{O}_{2}(\mathrm{~g})=\mathrm{SiO}_{2}(\mathrm{~s})+\mathrm{CO}_{2}(\mathrm{~g})
\end{gathered}
$$

For Reaction (1), the sequence of phase formation at temperatures below $1400{ }^{\circ} \mathrm{C}$ is $\mathrm{Al}_{2} \mathrm{O}_{3}>\mathrm{B}_{2} \mathrm{O}_{3}>\mathrm{MoO}_{3}$ [29]. Before a dense and continuous $\mathrm{Al}_{2} \mathrm{O}_{3}$ scale forms, $\mathrm{B}_{2} \mathrm{O}_{3}$ and $\mathrm{MoO}_{3}$ evaporate, thus causing the weight loss upon oxidation at temperatures above $1200{ }^{\circ} \mathrm{C}$ [15]. Once the dense and continuous $\mathrm{Al}_{2} \mathrm{O}_{3}$ scale forms, it acts as a barrier to prevent the inward diffusion of $\mathrm{O}$ and the outward diffusion of $\mathrm{B}$ and Mo, decreasing the evaporation rate of $\mathrm{MoO}_{3}$ and $\mathrm{B}_{2} \mathrm{O}_{3}$. Therefore, the weight gain is predominant in the MoAlB material during oxidation at high temperatures.

For the oxidation of SiC/MoAlB composites, both Reactions (1) and (2) occur. Reaction (2) induced a fluid glassy phase of $\mathrm{SiO}_{2}$ at above $1200{ }^{\circ} \mathrm{C}$, similar to the oxidation reaction in a $\mathrm{SiC} / \mathrm{Ti}_{3} \mathrm{Si}(\mathrm{Al}) \mathrm{C}_{2}$ composite [22]. The fluid phase fills some pores and accelerates the formation of dense and continuous oxide scale, decreasing the oxidation rate and leading to the thinner oxide scale on the $\mathrm{SiC} / \mathrm{MoAlB}$ as compared to the pure MoAlB material. 
A cross-sectional back-scattered SEM micrograph presents the microstructure of scale after oxidation at $1300{ }^{\circ} \mathrm{C}$ for $10 \mathrm{~h}$ in air. It should be noted that the formed $\mathrm{SiO}_{2}$ is just over a $\mathrm{SiC}$ particle (Fig. 8(a)). The two phases are identified by EDS mapping, as shown in Fig. 8(b). This feature suggests that the $\mathrm{SiC}$ particles on the surface are gradually in situ oxidized to $\mathrm{SiO}_{2}$. The small and round pore can be found in the $\mathrm{SiO}_{2}$ particle, which should be resulted from the evaporation of $\mathrm{CO}_{2}$ according to Reaction (2) at $1300{ }^{\circ} \mathrm{C}$. It is reasonable to believe that fine $\mathrm{SiC}$ particles in the MoAlB will further improve the oxidation resistance of composites due to the fact that the fine reinforcement leads to the rapid formation of $\mathrm{SiO}_{2}$ which seals microcracks and channels in the $\mathrm{Al}_{2} \mathrm{O}_{3}$ scale to retard the evaporation of $\mathrm{B}_{2} \mathrm{O}_{3}$ and $\mathrm{MoO}_{3}$ in the initial oxidation stage.

Based on the above results, a proposed oxidation resistance mechanism for $\mathrm{SiC} / \mathrm{MoAlB}$ is presented in Fig. 9. Before the formation of a continuous $\mathrm{Al}_{2} \mathrm{O}_{3}$ and $\mathrm{SiO}_{2}$ scale, the evaporation of $\mathrm{MoO}_{3}, \mathrm{~B}_{2} \mathrm{O}_{3}$, and $\mathrm{CO}_{2}$ at
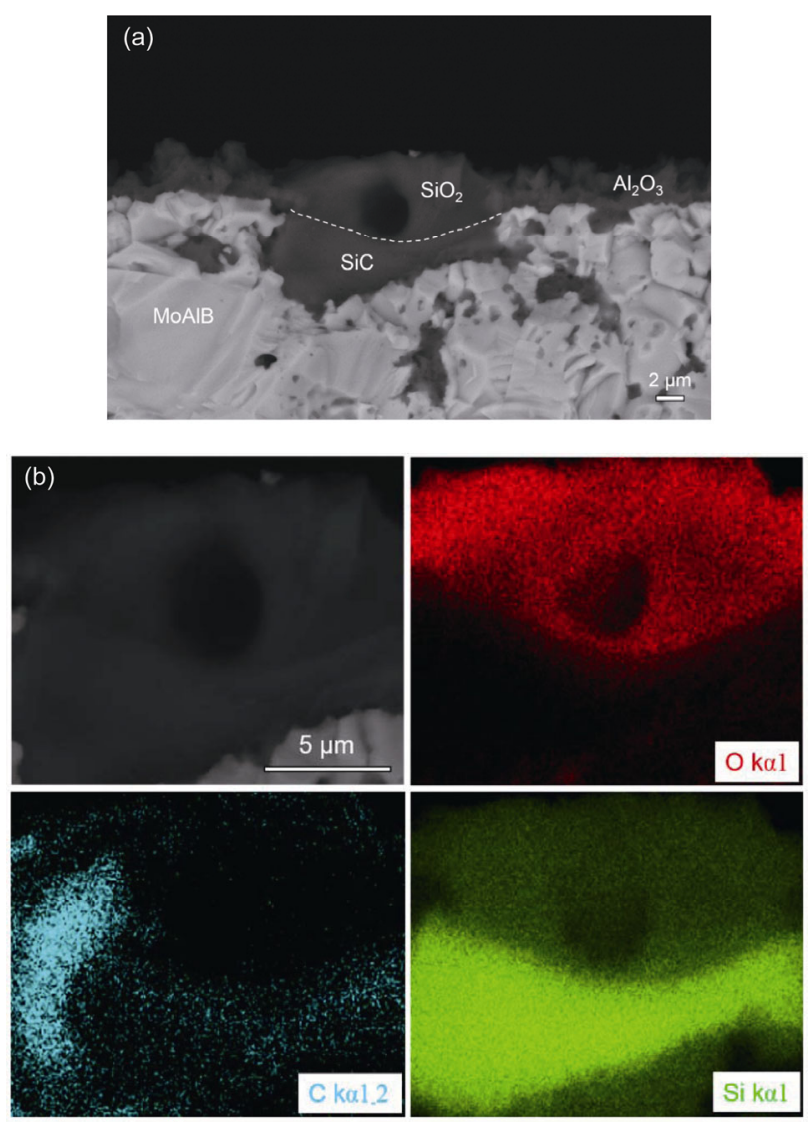

Fig. 8 (a) Cross-sectional back-scattered SEM micrograph and (b) corresponding EDS mapping of $5 \mathrm{vol} \% \mathrm{SiC} / \mathrm{MoAlB}$ composite after oxidation at $1300{ }^{\circ} \mathrm{C}$ for $10 \mathrm{~h}$ in air.

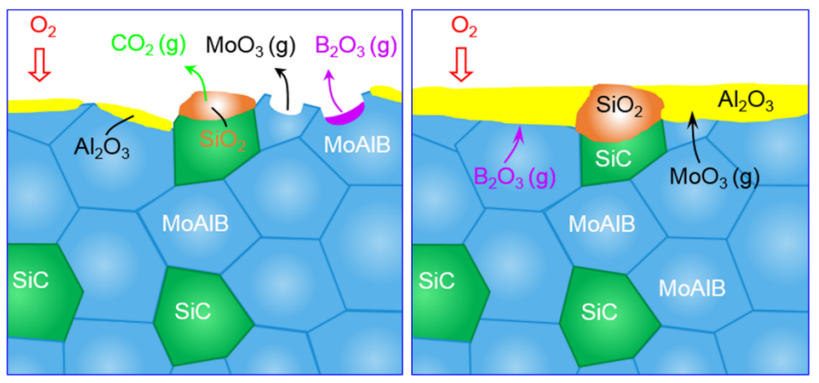

Fig. 9 Schematic of the oxidation mechanism of $\mathrm{SiC} / \mathrm{MoAlB}$ as exposed to air.

above $1200{ }^{\circ} \mathrm{C}$ induces the weight loss at early oxidation stage. However, the fluid glass of $\mathrm{SiO}_{2}$ formed at above $1200{ }^{\circ} \mathrm{C}$ can seal phase boundaries and fill small pores for retarding the inward diffusion of oxygen. Hence, the oxidation resistance of $\mathrm{SiC} / \mathrm{MoAlB}$ is better than that of MoAlB even at early oxidation stage. Once the continuous and dense scale forms, the inward diffusion rate of oxygen is retarded, and a low oxygen partial pressure under the scale generates. As a result, the oxidation of Mo and $\mathrm{B}$ followed by evaporation of $\mathrm{MoO}_{3}$ and $\mathrm{B}_{2} \mathrm{O}_{3}$ is suppressed, leading to weight gain. In addition, the fluid glass of $\mathrm{SiO}_{2}$ will fill microcracks and small pores in the scale, and further increases the bonding strength between the oxide scale and the matrix. The above analysis explains the reason why $\mathrm{SiC} / \mathrm{MoAlB}$ has thinner oxide scales than MoAlB after oxidation at 1200 and $1300{ }^{\circ} \mathrm{C}$.

\section{Conclusions}

5-15 vol\% SiC/MoAlB composites were prepared by hot pressing of $\mathrm{SiC}$ and $\mathrm{MoAlB}$ at $1200{ }^{\circ} \mathrm{C}$ under $25 \mathrm{MPa}$ for $1 \mathrm{~h}$ in Ar atmosphere. Such hot pressing conditions led to $\sim 92.6 \%$ theoretical density in the $5 \mathrm{vol} \% \mathrm{SiC} / \mathrm{MoAlB}$ composite, close to $93 \%$ for MoAlB. Increasing $\mathrm{SiC}$ content in composites induces the decrease in density. SiC and MoAlB are chemically stable without any reaction products at the sintering temperature of $1200{ }^{\circ} \mathrm{C}$. The $5 \mathrm{vol} \% \mathrm{SiC} / \mathrm{MoAlB}$ composite is stronger and harder than MoAlB. A flexural strength of $380 \mathrm{MPa}$ and a Vickers hardness of $12.7 \mathrm{GPa}$ were achieved in the $5 \mathrm{vol} \% \mathrm{SiC} / \mathrm{MoAlB}$ composite and increased by $24 \%$ and $51 \%$, respectively, as compared with those for MoAlB. In addition, the incorporation of $\mathrm{SiC}$ also improved the oxidation resistance of MoAlB due to the formation of a dense and continuous scale composed of $\mathrm{Al}_{2} \mathrm{O}_{3}$ and 
$\mathrm{SiO}_{2}$, which prevents the oxygen inward diffusion and the evaporation of oxides.

\section{Acknowledgements}

This work was supported by the National Natural Science Foundation of China (No. 51772020) and Beijing Government Funds for the Constructive Project of Central Universities.

\section{References}

[1] Ade M, Hillebrecht $\mathrm{H}$. Ternary borides $\mathrm{Cr}_{2} \mathrm{AlB}_{2}, \mathrm{Cr}_{3} \mathrm{AlB}_{4}$ and $\mathrm{Cr}_{4} \mathrm{AlB}_{6}$ : The first members of the series $\left(\mathrm{CrB}_{2}\right)_{n} \mathrm{CrAl}$ with $n=1,2,3$ and a unifying concept for ternary borides as MAB-phases. Inorg Chem 2015, 54: 6122-6135.

[2] Kota S, Sokol M, Barsoum MW. A progress report on the MAB phases: Atomically laminated, ternary transition metal borides. Int Mater Rev 2020, 65: 226-255.

[3] Bai Y, Qi X, Duff A, et al. Density functional theory insights into ternary layered boride MoAlB. Acta Mater 2017, 132: 69-81.

[4] Lu J, Kota S, Barsoum MW, et al. Atomic structure and lattice defects in nanolaminated ternary transition metal borides. Mater Res Lett 2017, 5: 235-241.

[5] Xiang H, Feng Z, Li Z, et al. Theoretical investigations on mechanical and dynamical properties of MAlB $(\mathrm{M}=\mathrm{Mo}, \mathrm{W})$ nanolaminated borides at ground-states and elevated temperatures. J Alloys Compd 2018, 738: 461-472.

[6] Kota S, Agne M, Zapata-Solvas E, et al. Elastic properties, thermal stability, and thermodynamic parameters of MoAlB. Phys Rev B 2017, 95: 144108.

[7] Su X, Dong J, Chu L, et al. Synthesis, microstructure and properties of MoAlB ceramics prepared by in situ reactive spark plasma sintering. Ceram Int 2020, 46: 1521415221.

[8] Xu L, Shi O, Liu C, et al. Synthesis, microstructure and properties of MoAlB ceramics. Ceram Int 2018, 44: 13396-13401.

[9] Chen Y, Kota S, Barsoum MW, et al. Compressive deformation of MoAlB up to $1100{ }^{\circ} \mathrm{C}$. J Alloys Compd 2019, 774: 1216-1222.

[10] Zhang H, Kim JY, Su R, et al. Defect behavior and radiation tolerance of $\mathrm{MAB}$ phases $\left(\mathrm{MoAlB}\right.$ and $\mathrm{Fe}_{2} \mathrm{AlB}_{2}$ ) with comparison to MAX phases. Acta Mater 2020, 196: 505-515.

[11] Bei G, van der Zwaag S, Kota S, et al. Ultra-high temperature ablation behavior of MoAlB ceramics under an oxyacetylene flame. J Eur Ceram Soc 2019, 39: 2010-2017.

[12] $\mathrm{Su} \mathrm{X,} \mathrm{Hu} \mathrm{B,} \mathrm{Quan} \mathrm{Y,} \mathrm{et} \mathrm{al.} \mathrm{Ablation} \mathrm{behavior} \mathrm{and}$ mechanism of bulk MoAlB ceramic at $\sim 1670-2550{ }^{\circ} \mathrm{C}$ in air plasma flame. J Eur Ceram Soc 2021, 41: 54745483.

[13] Bai Y, Sun D, Li N, et al. High-temperature mechanical properties and thermal shock behavior of ternary-layered MAB phases $\mathrm{Fe}_{2} \mathrm{AlB}_{2}$. Int J Refract Met Hard Mater 2019, 80: $151-160$.

[14] Zhang H, Xiang H, Dai FZ, et al. Oxidation behavior and thermal stability of $\mathrm{Cr}_{2} \mathrm{AlB}_{2}$ powders. Corros Sci 2020, 176: 108941 .

[15] Mou JJ, Li SB, Yao BX, et al. Cyclic oxidation behavior of MoAlB in the temperature range $450-850{ }^{\circ} \mathrm{C} . J$ Alloys Compd 2020, 831: 154802.

[16] Kota S, Zapata-Solvas E, Ly A, et al. Synthesis and characterization of an alumina forming nanolaminated boride: MoAlB. Sci Rep 2016, 6: 26475.

[17] Basu S, Obando N, Gowdy A, et al. Long-term oxidation of $\mathrm{Ti}_{2} \mathrm{AlC}$ in air and water vapor at $1000-1300{ }^{\circ} \mathrm{C}$ temperature range. J Electrochem Soc 2012, 159: C90.

[18] Li SB, Chen XD, Zhou Y, et al. Influence of grain size on high temperature oxidation behavior of $\mathrm{Cr}_{2} \mathrm{AlC}$ ceramics. Ceram Int 2013, 39: 2715-2721.

[19] Yao BX, Li SB, Ma PF, et al. Oxidation behavior of $\mathrm{MoAl}_{0.97} \mathrm{Si}_{0.03} \mathrm{~B}$ solid solution at $1200-1400{ }^{\circ} \mathrm{C}$. Mater Today Commun 2020, 22: 100846.

[20] Ma PF, Li SB, Hu J, et al. Processing and characterization of $\mathrm{MoAl}_{1-x} \mathrm{Si}_{x} \mathrm{~B}$ solid solutions. J Alloys Compd 2020, 814: 152290 .

[21] Li SB, Xie JX, Zhang LT, et al. Mechanical properties and oxidation resistance of $\mathrm{Ti}_{3} \mathrm{SiC}_{2} / \mathrm{SiC}$ composite synthesized by in situ displacement reaction of $\mathrm{Si}$ and TiC. Mater Lett 2003, 57: 3048-3056.

[22] Li SB, Song GM, Zhou Y. A dense and fine-grained $\mathrm{SiC} / \mathrm{Ti}_{3} \mathrm{Si}(\mathrm{Al}) \mathrm{C}_{2}$ composite and its high-temperature oxidation behavior. J Eur Ceram Soc 2012, 32: 34353444.

[23] Barsoum MW, Ho-Duc LH, Radovic M, et al. Long time oxidation study of $\mathrm{Ti}_{3} \mathrm{SiC}_{2}, \mathrm{Ti}_{3} \mathrm{SiC}_{2} / \mathrm{SiC}$, and $\mathrm{Ti}_{3} \mathrm{SiC}_{2} / \mathrm{TiC}$ composites in air. J Electrochem Soc 2003, 150: B166.

[24] Wan DT, Zhou YC, Hu CF, et al. Improved strengthimpairing contact damage resistance of $\mathrm{Ti}_{3} \mathrm{Si}(\mathrm{Al}) \mathrm{C}_{2} / \mathrm{SiC}$ composites. J Eur Ceram Soc 2007, 27: 2069-2076.

[25] Zhang J, Wang L, Jiang W, et al. High temperature oxidation behavior and mechanism of $\mathrm{Ti}_{3} \mathrm{SiC}_{2}-\mathrm{SiC}$ nanocomposites in air. Compos Sci Technol 2008, 68: 1531-1538.

[26] Zhou X, Jing L, Kwon YD, et al. Fabrication of $\mathrm{SiC}_{\mathrm{w}} /$ $\mathrm{Ti}_{3} \mathrm{SiC}_{2}$ composites with improved thermal conductivity and mechanical properties using spark plasma sintering. $J$ Adv Ceram 2020, 9: 462-470.

[27] Lu XG, Li SB, Zhang WW, et al. Thermal shock behavior of a nanolaminated ternary boride: MoAlB. Ceram Int 2019, 45: 9386-9389. 
[28] Reddy V, Sonber JK, Sairam K, et al. Densification and mechanical properties of $\mathrm{CrB}_{2}+\mathrm{MoSi}_{2}$ based novel composites. Ceram Int 2015, 41: 7611-7617.

[29] Lu XG, Li SB, Zhang WW, et al. Crack healing behavior of a MAB phase: MoAlB. J Eur Ceram Soc 2019, 39: 4023-4028.

Open Access This article is licensed under a Creative Commons Attribution 4.0 International License, which permits use, sharing, adaptation, distribution and reproduction in any medium or format, as long as you give appropriate credit to the original author(s) and the source, provide a link to the Creative Commons licence, and indicate if changes were made.

The images or other third party material in this article are included in the article's Creative Commons licence, unless indicated otherwise in a credit line to the material. If material is not included in the article's Creative Commons licence and your intended use is not permitted by statutory regulation or exceeds the permitted use, you will need to obtain permission directly from the copyright holder.

To view a copy of this licence, visit http://creativecommons. org/licenses/by/4.0/. 